\title{
Disinflation with labor market frictions
}

\author{
January 2014
}

\begin{abstract}
This paper studies disinflationary shocks in a non-linear New Keynesian model with search and matching frictions and moral hazard in the labor markets. Our focus is on understanding the wage formation process as well as welfare costs of disinflations in the presence of such labor market frictions.

The presence of imperfect information in labor markets imposes a lower bound on worker surplus that varies endogenously. Consequently equilibrium can take two forms depending on whether the no shirking condition is binding or not. We also evaluate both regimes from a welfare perspective when the economy is subject to a perfectly credible disinflationary shock.
\end{abstract}

KeYwords: Disinflation, Labor market frictions, Welfare costs JEL Classification: E24, E31, J64 


\section{Introduction}

Over the past decade the New Keynesian (NK) model has emerged as the workhorse of modern monetary economics. However, its assumption of Walrasian labor markets means that it does not address the issue of involuntary unemployment. To explain the presence of involuntary unemployment, standard models depart from the Walrasian paradigm by introducing moral hazard or search and matching frictions in the wage formation process. In this paper we incorporate both these labor market frictions into a standard New Keynesian model and study the wage formation process when the economy is subject to disinflationary shocks. Further we also evaluate the welfare costs of disinflation in the presence of these labor market frictions.

The presence of moral hazard in addition to search and matching frictions in the labor market means wages must satisfy a no-shirking condition (NSC), which places a lower bound on workers' match surplus. Our objective is then to characterize the circumstances under which this lower bound becomes binding and the threat to shirk becomes credible. In doing so we show that the wage formation process is different in high and low inflation environments. We also evaluate the welfare costs of a fully credible disinflation process in such a milieu and find it to be critically affected by the nature of the labor market frictions.

Importantly, we analyze the impact of the disinflationary shock in a non-linear NK setup. Ascari and Merkl (2009) point out that the analysis of the real effects of a disinflation in much of the literature is flawed because it is based on the log-linear formulation of the standard NK model. This is because a permanent disinflationary shock would require a movement from one steady state to a new one and therefore cannot be analyzed by log-linearizing the model around one of the two steady states.

We introduce shirking in the NK search and matching framework of Ravenna and Walsh (2011) by assuming that the firm's ability to monitor the effort put in 
by the worker is imperfect. The surplus from being employed is therefore affected by the presence of search and matching frictions and moral hazard. Hence, the equilibrium can take two forms depending on whether the no-shirking condition NSC is binding or not. The wage is called an efficiency wage (EW) if the NSC is binding and a Nash Bargaining wage (NB) otherwise. Importantly, the boundary between the two regimes is shown to be dependent on the inflation rate in the economy. ${ }^{1}$

We next turn to an analysis of permanent disinflationary shock. In the event of a permanent disinflationary shock the threat to shirk is non-credible and the labor market is characterized by Nash bargaining (NB) regime. To understand this, note that the long-run trade-off between steady state inflation and output is highly nonlinear in the New Keynesian framework. ${ }^{2}$ This is because two effects are at work. First, within the Calvo-type model, forward-looking firms set prices to take account of discounted expected future profits. Under a positive discount rate, current profits obtain a greater weight than future profits, and firms set a lower price than under a discount rate of zero. This feature generates a positive inflation-output relationship. Second, positive inflation increases price dispersion, which acts like a negative productivity shock. The price dispersion effect, therefore, generates a negative inflation-output trade-off, which under reasonable parameter assumptions dominates the positive time-discounting effect.

A permanent disinflationary shock therefore diminishes the price dispersion in the long run and acts as a permanent increase in labor productivity. The resulting increase in output causes an increase in the labor market tightness as firms post more vacancies and the unemployment rate falls. Indeed, in a tight labour market, turnover costs are high and workers can obtain a wage superior to the EW.

We next proceed to evaluate a credible disinflation program from a welfare

\footnotetext{
${ }^{1}$ Rocheteau (2001) carries out a related analysis in a non-monetary economy.

${ }^{2}$ See Ascari (2004), Ascari and Merkl (2009).
} 
perspective. Specifically we examine two cases (a) when the economy is characterized by NB wages and (b) when the economy is characterized by EW. We find that the EW regime, leads to higher output and welfare in the long run when compared to the NB regime.

There is a large literature that has incorporated labor market frictions into NK models. ${ }^{3}$ The focus of these earlier contributions has ranged from exploring how search and matching frictions affect the empirical performance of the New Keynesian model to studying optimal monetary policy in the presence of these frictions. These papers however do not address the issue of either wage formation process in the presence of labor market frictions during disinflations or how the welfare costs of disinflation are affected by the presence of such frictions.

The papers closest in motivation to ours are Ascari and Ropele (2012) and Rocheteau (2001). Rocheteau (2001) combines the shirking and the matching approaches in a non-monetary model in order to characterize the steady state wage formation process as a function of labor market conditions. Ascari and Ropele (2012) consider a medium scale non-linear NK model and focus on the welfare cost of disinflations. In an insightful paper, they show that disinflation despite its prolonged slump in output results in small welfare gains. Intuitively, permanent disinflationary shocks increase labor productivity in a non-linear NK model which causes output to rise in the long run. The long-run increase in output outweighs the short-run costs of recession resulting in an overall increase in welfare. We also study the disinflation process in a NK model. However, our work, with its explicit modelling of labor market frictions, focusses on the wage formation process as well as the welfare costs in the presence of such labor market frictions.

The rest of the paper is organized as follows. In Section 2 we present our basic

\footnotetext{
${ }^{3}$ Examples include Blanchard and Galí (2007), Krause and Lubik (2007), Faia (2008), Krause et al. (2008), Ravenna and Walsh (2008, 2011), Thomas (2008), Gertler et al. (2008), Gertler and Trigari (2009), and Trigari (2009).
} 
model. Section 3 describes the steady state properties of the economy, Section 4 analyzes the impact of a permanent disinflationary shock to the economy, Section 5 analyzes the welfare implications of a disinflationary shock under the two labor market regimes and Section 6 concludes. Technical details of the model are provided in an appendix.

\section{The Model}

The model closely follows Ravenna and Walsh (2011). It consists of households whose utility depends on the consumption of market and home produced goods. Households and firms are risk neutral. The members of households are either employed by wholesale goods producing firms or are unemployed. In the former case they receive a market real wage $w_{t}$; in the latter case they receive a fixed amount $w^{u}$ of household production units. When choosing employment and the real wage, firms face an efficiency wage constraint, which they have to satisfy in order to avoid shirking by workers. Wholesale goods are, in turn, purchased by retail firms who sell to households. The retail goods market is characterized by monopolistic competition. In addition, retail firms have sticky prices that adjust according to a standard Calvo specification.

\subsection{Households}

The household's lifetime utility at time $t$ is given by:

$$
E_{t} \sum_{i=0}^{\infty} \beta^{i}\left[C_{t+i}-e_{t+i}\right]
$$

where $e_{t}$ is the worker's effort level. We follow the literature on matching frictions and assume that the consumption risks are fully pooled. Following Shapiro and Stiglitz (1984), there are two levels of work intensity $e_{t}=\bar{e}$ or $e_{t}=0$ and worker's effort is imperfectly observed by employers. Total consumption $C_{t}$ consists of 
market goods $C_{t}^{m}$ and home production $w^{u}\left(1-N_{t}\right)$ :

$$
C_{t}=C_{t}^{m}+w^{u}\left(1-N_{t}\right)
$$

where $N_{t}$ is the number of household members employed during period $t$. Market consumption is an aggregate of goods purchased from a continuum of retail firms, indexed by $j \in[0,1]$, that produce differentiated final goods.

$$
C_{t}^{m} \leq\left[\int_{0}^{1} C_{t}^{m}(j)^{\frac{\epsilon-1}{\epsilon}} d j\right]^{\frac{\epsilon}{\epsilon-1}}
$$

The optimal intratemporal choice among goods implies

$$
C_{t}^{m}(j)=\left[\frac{P_{t}^{j}}{P_{t}}\right]^{-\epsilon} C_{t}^{m}, \text { where } P_{t}=\left[\int_{0}^{1} P_{t}(j)^{1-\epsilon} d j\right]^{\frac{1}{1-\epsilon}}
$$

The price of a unit of the consumption basket is $P_{t}$. The budget constraint of the household is given by

$$
P_{t} C_{t}+q_{t} B_{t+1}=P_{t}\left[w_{t} N_{t}+w^{u}\left(1-N_{t}\right)\right]+B_{t}+P_{t} \Pi_{t}^{r}
$$

where $B_{t}$ is the amount of riskless nominal bonds held by the household with price equal to $q_{t}$ and $\Pi_{t}^{r}$ denotes the profit from the retail sector. Household's maximize (1) subject to (2) and the intertemporal first order condition yields the standard Euler equation

$$
1=\beta E_{t}\left[i_{t} \frac{P_{t}}{P_{t+1}}\right]
$$

where $i_{t}$ is the gross nominal interest rate on an asset paying one unit of the consumption aggregate (currency) in any state of the world.

\subsection{Wholesale Firms}

Firms in the wholesale sector employ labor and produce output through the production function

$$
Y_{i t}^{m}=N_{i t}
$$


A wholesale firm must post vacancies to hire new employees, paying a cost of $P_{t} \kappa$ for each vacancy it posts. In order to post $v_{t}$ vacancies, wholesale firms buy individual final goods $v_{t}(j)$ from each $j$ final-goods-producing retail firm. As shown by Ravenna and Walsh (2011) the wholesale firm essentially solves a static problem wherein it minimizes total expenditure on job posting costs,

$$
\kappa \int_{0}^{1} P_{t}(j) v_{t}(j) d j
$$

subject to the constraint that the production function of a unit of final good aggregate $v_{t}$ is

$$
\left[\int_{0}^{1} v_{t}(j)^{\frac{\epsilon-1}{\epsilon}} d j\right]^{\frac{\epsilon}{\epsilon-1}} \geq v_{t}
$$

The demand by wholesale firms for the final goods produced by retail firm $j$ is therefore given by

$$
v_{t}(j)=\left[\frac{P_{t}^{j}}{P_{t}}\right]^{-\epsilon} v_{t}
$$

Total expenditure on final goods by households and wholesale firms is

$$
\int_{0}^{1} P_{t}(j) C_{t}^{m}(j) d j+\kappa \int_{0}^{1} P_{t}(j) v_{t}(j) d j=P_{t}\left(C_{t}^{m}+\kappa v_{t}\right)
$$

Wholesale firms sell their output in a competitive market at the price $P_{t}^{w}$. The real value of the firm's output, expressed in terms of time $t$ consumption goods, is $\frac{P_{t}^{w} Y_{i t}}{P_{t}}=\frac{Y_{i t}}{\mu_{t}}$, where $\mu_{t}=\frac{P_{t}}{P_{t}^{w}}$ is the markup of retail over wholesale prices.

\subsection{Retail Firms}

Each retail firm purchases wholesale output which it converts into a differentiated final good sold to households and wholesale firms. The retail firms' cost minimization problem implies

$$
M C_{t}^{n}=P_{t} M C_{t}=P_{t}^{w}
$$


where $M C_{t}^{n}$ is the nominal marginal cost of the firm. Note that the real marginal cost of the retail firms is the price of the wholesale good relative to the price of the final good, $\frac{P_{t}^{w}}{P_{t}}$. Retail firms adjust prices according to the Calvo updating model. In each period, a firm can adjust its price with probability $1-\omega$. Since all firms that adjust their price are identical, they all set the same price. Given $M C_{t}^{n}$, the retail firm chooses $P_{t}(j)$ to maximize

$$
\sum_{i=0}^{i=\infty}(\omega \beta)^{i} E_{t}\left[\frac{P_{t}(j)-M C_{t+i}^{n}}{P_{t+i}} Y_{t+i}(j)\right]
$$

subject to

$$
Y_{t+i}(j)=\left[\frac{P_{t}(j)}{P_{t+i}}\right]^{-\epsilon} Y_{t}^{d}
$$

where $Y_{t}^{d}$ is the aggregate demand for the final goods basket. This results in the standard pricing equation where the real marginal costs given by $\frac{P_{t}^{w}}{P_{t}}=\frac{1}{\mu_{t}}$ turn out to be the driving force behind inflation.

$$
\widetilde{P}_{t}=P_{t}(j)=\left(\frac{\epsilon}{\epsilon-1}\right) \frac{E_{t} \sum_{i=0}^{\infty}(\omega \beta)^{i}\left(\frac{1}{P_{t+i}}\right)^{1-\epsilon} Y_{t+i}(j) M C_{t+i}^{n}}{E_{t} \sum_{i=0}^{\infty}(\omega \beta)^{i}\left(\frac{1}{P_{t+i}}\right)^{1-\epsilon} Y_{t+i}(j)}
$$

As is standard in the literature, it can be shown that the aggregate price level evolves according to (See Appendix (A.2) for details)

$$
1=\left[\omega \pi_{t}^{\epsilon-1}+(1-\omega)\left(\frac{\widetilde{P}_{t}}{P_{t}}\right)^{1-\epsilon}\right]^{\frac{1}{1-\epsilon}}
$$

\subsection{Employment}

The labor market is characterized by search frictions. In each period $t$, a worker is either employed in a wholesale goods firm or unemployed. At the beginning of each period $t$, a share $\rho$ of the matches $N_{t-1}$ which engaged in production in period $t-1$ breaks up. The number of job seekers in period $t$ is therefore given 
$\mathrm{by}^{4}$

$$
u_{t}=1-(1-\rho) N_{t-1}
$$

The number of matches formed in period $t$ is a given by a matching function $m_{t}=m\left(u_{t}, v_{t}\right)=\chi v_{t}^{\alpha} u_{t}^{1-\alpha}$ where $v_{t}$ is the number of vacancies the firm posts and $u_{t}$ is the number of job seekers in period $t$. The measure of labor market tightness is denoted by $\theta_{t}=v_{t} / u_{t}$. The number of workers employed at time $t$ is given by

$$
N_{t}=(1-\rho) N_{t-1}+v_{t} q_{t}
$$

where $q_{t}=\frac{m_{t}}{v_{t}}=\chi \theta_{t}^{\alpha-1}$ is the probability of filling a vacancy. Employed workers receive net real wage $w_{t}$, while unemployed workers engage in home production which offers fixed real output of $w^{u}$. Thereafter, production starts and the individual worker employed in a firm decides upon his effort $e_{t}$. A worker may either choose to work, i.e. to display effort $e_{t}=\bar{e}$ or to shirk, $e_{t}=0$. The firm assesses the worker's effort from a fixed technology such that the individual worker faces probability $d$ of being detected when shirking. In such case, he is fired at the end of period $t$. Since there is zero productivity while shirking, an active equilibrium with positive production is such that the incentive-compatibility constraint is always fulfilled.

A non-shirker is a worker who chooses not to shirk in all periods while attached to the current job. The lifetime expected utility of a non-shirker who earns wage $w$ is denoted by $V^{E}$ and obeys the following asset pricing equation:

$$
V_{t}^{E}=w_{t}-\bar{e}+\beta E_{t}\left\{(1-\rho) V_{t+1}^{E}+\rho\left[p_{t+1} V_{t+1}^{E}+\left(1-p_{t+1}\right) V_{t+1}^{U}\right]\right\}
$$

since a worker is exogenously separated with probability $\rho$ but finds another match with probability $p_{t+1}=\frac{m_{t+1}}{u_{t+1}}=\theta_{t+1} q_{t+1}$, and fails to find a match with

\footnotetext{
${ }^{4}$ We follow Ravenna and Walsh (2011) and take the number of job seekers $u_{t}$ as the measure of unemployment. The more conventional measure of unemployment would equal the number of workers not in a match at the end of the period, $1-N_{t}$. In this framework the two are related since $u_{t+1}$ is equal to $1-N_{t}$ plus the number of exogenous separations $\rho N_{t}$.
} 
probability $1-p_{t+1}$. The value function for being unemployed is

$$
V_{t}^{U}=w^{u}+\beta E_{t}\left[\left(1-p_{t+1}\right) V_{t+1}^{U}+p_{t+1} V_{t+1}^{E}\right]
$$

Thus, the surplus value of a match to a non-shirking worker is

$$
V_{t}^{E}-V_{t}^{U}=w_{t}-\bar{e}-w^{u}+\beta E_{t}\left[(1-\rho)\left(1-p_{t+1}\right)\left(V_{t+1}^{E}-V_{t+1}^{U}\right)\right]
$$

The lifetime expected utility of a currently employed worker who chooses to shirk during period $t$ is given by

$$
\left.\begin{array}{c}
V_{t}^{S}=(1-d) w_{t}+\beta E_{t}\left\{d\left[p_{t+1} \max \left[V_{t+1}^{E}, V_{t+1}^{S}\right]+\left(1-p_{t+1}\right) V_{t+1}^{U}\right]\right. \\
+(1-d) \rho\left[p_{t+1} \max \left[V_{t+1}^{E}, V_{t+1}^{S}\right]+\left(1-p_{t+1}\right) V_{t+1}^{U}\right] \\
+(1-d)(1-\rho) \max \left[V_{t+1}^{E}, V_{t+1}^{S}\right]
\end{array}\right\}
$$

where $d$ is the probability of being detected. Here we make an assumption that a worker loses his job if he is caught shirking. It follows that the no-shirking condition (NSC) is given by

$$
V_{t}^{E}-V_{t}^{S} \geq 0
$$

In other words a rational worker will never shirk if the gain from shirking is less than the expected cost of a layoff in case of detection. Since the NSC is always satisfied in active equilibria, the surplus value from not shirking is given by

$$
V_{t}^{E}-V_{t}^{S}=d w_{t}-\bar{e}+\beta E_{t}\left[(1-\rho)\left(1-p_{t+1}\right) d\left(V_{t+1}^{E}-V_{t+1}^{U}\right)\right]
$$

We now focus on the wholesale firm's hiring decisions. The profit maximizing condition can be summarized as (See Appendix (A.1) for details)

$$
w_{t}=\frac{1}{\mu_{t}}-\frac{\kappa}{q_{t}}+\beta(1-\rho) E_{t} \frac{\kappa}{q_{t+1}}
$$

The real wage equals the marginal product of labor $\frac{1}{\mu_{t}}$, minus the expected cost of hiring the matched worker $\frac{\kappa}{q_{t}}$, plus the reduction in future search costs. The 
firm must post vacancies to hire workers, the value of these vacancies is zero in equilibrium under free entry. Formally, this implies

$$
V_{t}^{J}=\frac{\kappa}{q_{t}}
$$

where $V_{t}^{J}$ is the value of a filled job and $q_{t}$ is the probability of filling it. For future reference we can combine (16) and (17) to get

$$
V_{t}^{J}=\frac{1}{\mu_{t}}-w_{t}+\beta(1-\rho) E_{t} V_{t+1}^{J}
$$

which implies that the value of a filled job is equal to the firm's current surplus plus the discounted value of continuing the match in the following period.

\subsection{Wages}

The wage flow $w$ that will be paid to the worker during the lifetime of the job is determined through bilateral bargaining. The worker's bargaining power is denoted by $b$. Furthermore, the NSC gives the minimum wage that must be paid by an employer to prevent his worker from shirking. Indeed, an employer will never agree to pay a wage which does not satisfy the incentive constraint. The Nash problem can be written as follows

$$
\max \left(V_{t}^{E}-V_{t}^{U}\right)^{b}\left(V_{t}^{J}\right)^{1-b}
$$

subject to (14). Two cases can be distinguished: a binding and a non-binding NSC.

\subsubsection{Efficiency Wages}

When the freely negotiated wage violates the incentive constraint: the threat to

shirk is credible. It follows from (15) that when the NSC binds at time $t$, the wage rate is given by

$$
w_{t}^{E W}=\frac{\bar{e}}{d}-\beta E_{t}\left[(1-\rho)\left(1-p_{t+1}\right)\left(V_{t+1}^{E}-V_{t+1}^{U}\right)\right]
$$


where $w^{E W}$ is the endogenously determined wage rate. Using (19), we can rewrite (16) as

$$
\begin{aligned}
\frac{1}{\mu_{t}} & =\frac{P_{t}^{w}}{P_{t}} \\
& =\frac{\bar{e}}{d}+\frac{\kappa}{q_{t}}-\beta(1-\rho) E_{t}\left[\left(1-p_{t+1}\right)\left(V_{t+1}^{E}-V_{t+1}^{U}\right)+\frac{\kappa}{q_{t+1}}\right]
\end{aligned}
$$

Equation (20) is an expression for the relative price of wholesale goods in terms of retail goods under efficiency wages. Labor market tightness affects inflation through variations in the markup $\mu_{t}$. Intuitively, a rise in labor market tightness increases $\frac{\kappa}{q_{t}}$, which is the expected cost of hiring a worker. As a consequence of the resultant price rise in the wholesale sector, marginal costs increase in the retail sector. The increases marginal costs in the retail sector results in higher inflation.

The equation also underlines the impact of expectations of labor market tightness on inflation. Essentially, expectations of greater labor market tightness increases the value of existing matches, since it reduces future search costs. This has the effect of reducing marginal costs. On the other hand these expectations reduce the current surplus to a worker from an existing match by increasing the expected probability $p$ of an unemployed worker finding a job. This has the effect

of raising marginal costs. The net impact on marginal costs and hence inflation would depend on the strength of these two effects.

\subsubsection{Nash Bargaining Wages}

In this case the threat to shirk is not credible and the equilibrium wage, denoted by $w_{t}^{N B}$, is the wage that would be obtained at time $t$ in the absence of unobservable shirking, that is

$$
V_{t}^{E}-V_{t}^{U}=\frac{b}{1-b} V_{t}^{J}=\frac{b}{1-b} \frac{\kappa}{q_{t}}
$$


It follows from (12) that the Nash bargaining wage is given by

$$
w_{t}^{N B}=\frac{b}{1-b} \frac{\kappa}{q_{t}}+\bar{e}+w^{u}-\beta E_{t}\left[(1-\rho)\left(1-p_{t+1}\right)\left(V_{t+1}^{E}-V_{t+1}^{U}\right)\right]
$$

Substituting (12) in (16) we get

$$
\begin{aligned}
\frac{1}{\mu_{t}} & =\frac{P_{t}^{w}}{P_{t}} \\
& =\bar{e}+w^{u}+\frac{\kappa}{q_{t}(1-b)}-\beta(1-\rho) E_{t}\left[\left(1-p_{t+1}\right)\left(V_{t+1}^{E}-V_{t+1}^{U}\right)+\frac{\kappa}{q_{t+1}}\right]
\end{aligned}
$$

Once again a rise in labor market tightness increases marginal costs by reducing $q_{t}$ and expectations of a higher labor market tightness lowers the effective cost of current labor matches.

\subsection{Monetary Policy}

The monetary policy for the (gross) nominal interest rate, $i_{t}$, is assumed to be described by a standard interest rate rule:

$$
\left(\frac{i_{t}}{\bar{\imath}}\right)=\left(\frac{\pi_{t}}{\bar{\pi}}\right)^{\alpha_{\pi}}
$$

where $\pi_{t}$ is the gross inflation rate, $\bar{\pi}$ is the central bank inflation target.

\subsection{Market Clearing Conditions}

Goods market clearing requires that household consumption of market produced goods plus final goods purchased by wholesale firms to cover the costs of posting job vacancies equal the output of the retail sector:

$$
Y_{t}=C_{t}^{m}+\kappa v_{t}=C_{t}-w^{u}\left(1-N_{t}\right)+\kappa v_{t}
$$

Aggregate employment is given by

$$
\begin{aligned}
N_{t} & =\left[\int_{0}^{1} N_{i, t} d i\right]=\left[\int_{0}^{1} Y_{i, t} d i\right]=\left[\int_{0}^{1}\left(\frac{P_{i, t}}{P_{t}}\right)^{-\epsilon} Y_{t} d i\right] \\
& =s_{t} Y_{t}
\end{aligned}
$$


where $s_{t}$ is the price dispersion. Schmitt-Grohe and Uribe (2007) show that $s_{t}$ is bounded below at one, so that $s_{t}$ represents the resource cost due to relative price dispersion with long run inflation. Indeed the higher the $s_{t}$ the more the labor needed to produce a given level of output. The dynamics of $s_{t}$ is given by (See Appendix A.3)

$$
s_{t}=(1-\omega)\left(\frac{\widetilde{P}_{t}}{P_{t}}\right)^{-\epsilon}+\omega \pi_{t}^{\epsilon} s_{t-1}
$$

\section{$3 \quad$ Steady State Analysis}

A good starting point to analyze the disinflation experiment is to look at steady state in a full non-linear model.

\subsection{Inflation}

We now proceed to formally establish the link between inflation, and labor pro-

ductivity $\frac{1}{\mu}$ in steady state (See Appendix A.4). The steady state values in the non-stochastic steady states can simply be obtained by dropping the time indices. The steady state inflation is equal to the central banks inflation target $\pi=\bar{\pi}$.

$$
1=\omega \bar{\pi}^{\varepsilon-1}+(1-\omega)\left[\frac{\varepsilon}{\varepsilon-1} \frac{1}{\mu} \frac{\left(1-\omega \beta \bar{\pi}^{\varepsilon-1}\right)}{\left(1-\omega \beta \bar{\pi}^{\varepsilon}\right)}\right]^{1-\varepsilon}
$$

This equation establishes the equilibrium relationship between inflation and labor productivity. One can show that for reasonable parameters, that labor productivity varies inversely with steady state inflation. Essentially, positive inflation generates price dispersion, which generates a strong distortionary effects under Calvo price staggering. Thus an increase in inflation acts like a negative productivity shock and reduces the productivity of labor. Formally one can express this relationship as $\frac{1}{\mu}=f(\pi)$, where for reasonable parameter values $f^{\prime}(\pi)<0$. 


\subsection{Steady State Wages}

\subsubsection{Wages with no labor market frictions}

Consider first the case where there are no labor market frictions. This would imply that firms do not pay a cost to post a vacancy and thus $\kappa=0$, note in this case the economy will always be at its full employment. It follows from (16), the steady state wage in the absence of labor market frictions, $w^{o}$, is

$$
w^{o}=\frac{1}{\mu}
$$

\subsubsection{Wages with both shirking and search frictions}

When the labor market is subject to frictions, the steady state wages can take two forms depending on whether the NSC is binding or not. If the NSC condition is non-binding then we have an NB regime where wages are set according to Nash bargaining. On the other hand if the NSC is binding then we have an EW regime where the equilibrium wages are efficiency wages. We now proceed to derive the steady state conditions. The steady state value of the surplus associated with being employed follows from (12) and is given by

$$
V^{E}-V^{U}=\frac{w-\bar{e}-w^{u}}{1-\beta(1-\rho)(1-\theta q)}
$$

The NSC in steady state is given by

$$
V^{E}-V^{S}=d w-\bar{e}+d \beta(1-\rho)(1-\theta q)\left(V^{E}-V^{U}\right)
$$

The steady state value of job creation follows from (18) and is given by

$$
\frac{\kappa}{q} \frac{\rho+r}{1+r}=f(\bar{\pi})-w
$$

where $1+r=\frac{1}{\beta}$. Equation (30) is the so called vacancy supply condition and it shows that there is an inverse relationship between labor market tightness and real wage in steady state. 


\subsubsection{NSC is binding}

When the NSC is binding the threat to shirk is binding and efficiency wages result. Combining (28) and (19) we get an expression for efficiency wages

$$
w^{E W}=\left[1-\frac{(1-\rho)(1-\theta q)}{1+r}\right] \frac{\bar{e}}{d}+\frac{(1-\rho)(1-\theta q)\left(\bar{e}+w^{u}\right)}{1+r}
$$

The efficiency wages is a linear combination of workers reservation wages and effort. We can combine (30) and (31) to obtain the vacancy supply condition under the EW regime (See Appendix (A.5.1) for details)

$$
\frac{\kappa}{q} \frac{\rho+r}{1+r}=\left\{f(\bar{\pi})-\left[1-\frac{(1-\rho)(1-\theta q)}{1+r}\right] \frac{\bar{e}}{d}-\frac{(1-\rho)(1-\theta q)\left(\bar{e}+w^{u}\right)}{1+r}\right\}
$$

Substituting the steady state value of efficiency wages obtained in (28), we get an expression for the surplus associated with being employed under an EW regime

$$
V^{E}-V^{U}=\left(\frac{1-d}{d}\right) \bar{e}-w^{u}
$$

The EW regime occurs when the surplus associated with being employed in the NB regime is not enough to induce effort. Formally,

$$
\frac{b}{(1-b)} \frac{\kappa}{q} \leq\left(\frac{1-d}{d}\right) \bar{e}-w^{u}
$$

According to (33) when the workers rent arising from the moral hazard problem is greater than the rent arising from the presence of search frictions the equilibrium wage is an efficiency wage.

\subsubsection{NSC is not binding}

When the NSC is not binding the threat to shirk is not credible. The wage equilibrium wage denoted by $w^{N B}$ is the equilibrium wage that would be obtained in the absence of unobservable shirking. The expression for this steady state wage obtained under Nash bargaining is given by (See Appendix (A.5.2) for details)

$$
w^{N B}=b\left[f(\bar{\pi})+\frac{\theta \kappa(1-\rho)}{1+r}\right]+(1-b)\left(\bar{e}+w^{u}\right)
$$


The NB wage is a weighted average of the worker's productivity and the worker's reservation wages. Substituting (34) into (30) we get

$$
(1-b)\left[f(\bar{\pi})-\left(e+w^{u}\right)\right]=\frac{\kappa}{q} \frac{(\rho+r)}{(1+r)}+\frac{b \kappa \theta(1-\rho)}{1+r}
$$

Labor market tightness in steady state therefore is a decreasing function of the inflation rate, reservation wage and the disutility of effort wage. It follows that under the NB regime

$$
\frac{b}{(1-b)} \frac{\kappa}{q} \geq\left(\frac{1-d}{d}\right) \bar{e}-w^{u}
$$

\subsection{The Frontier Between the Two Regimes}

At the boundary between the two regimes the efficiency wages must equal the Nash bargaining wages. Let $(\bar{\pi}, \bar{\theta})$ denote the pair of variables that satisfy the following two equations

$$
\begin{gathered}
\frac{b}{(1-b)} \frac{\kappa}{q(\bar{\theta})}=\left(\frac{1-d}{d}\right) \bar{e}-w^{u} \\
(1-b)\left[f(\bar{\pi})-\left(\bar{e}+w^{u}\right)\right]=\frac{\kappa}{q(\bar{\theta})} \frac{(\rho+r)}{(1+r)}+\frac{b \kappa \bar{\theta}(1-\rho)}{1+r}
\end{gathered}
$$

The pair $(\bar{\pi}, \bar{\theta})$ also satisfies (32). From (32) if $\pi>\bar{\pi}, \theta<\bar{\theta}$ and (33) is satisfied: the equilibrium wage is an EW. From (35) if $\pi<\bar{\pi}, \theta>\bar{\theta}$ and (36) is satisfied. The equilibrium wage is then Nash bargaining.

Result: There is a threshold level of inflation $\bar{\pi}$ in steady state values above which result in an $E W$ regime and below which result in an NB regime.

Intuitively, high inflation increases price dispersion which acts like a negative productivity shock. Lower productivity reduces the surplus from being employed and hence the threat to shirk becomes credible resulting in an EW regime. Our key result here is that efficiency wages should be observed in high inflation environments and NB wages are more likely to be observed in low inflation environments. 
According to (9), the steady state level of unemployment is given by

$$
\bar{u}=\frac{\rho}{\rho+\bar{\theta} q(\bar{\theta})}
$$

It follows from the above equation that when $\pi>\bar{\pi}, \theta<\bar{\theta}$, then $u>\bar{u}$ and the wage is an EW wage and $\pi<\bar{\pi}, \theta>\bar{\theta}$, then $u<\bar{u}$ and the wage is an EW wage. In other words high inflation environments are associated with higher unemployment rates.

Proposition 1 The critical $\bar{\pi}$ above which $E W$ regime occurs depends on the bargaining power of workers $(b)$, inspection rate $(d)$, job posting costs $(\kappa)$ and job separation rate $(\rho)$. Furthermore,

$$
\frac{\partial \bar{\pi}}{\partial b}>0, \frac{\partial \bar{\pi}}{\partial d}>0, \frac{\partial \bar{\pi}}{\partial \kappa}>0, \frac{\partial \bar{\pi}}{\partial \bar{e}}<0, \frac{\partial \bar{\pi}}{\partial w^{u}}<0
$$

Proof. The pair $(\bar{\pi}, \bar{\theta})$ satisfies equations (37) and (38). An exogenous increase in $b$ raises the left hand side of (37), holding other parameters constant. To restore the equality, $\bar{\theta}$ has to fall (recall $q(\theta)=\chi \theta^{\alpha-1}$ ). The lower value of $\bar{\theta}$ decreases the left hand side of (38). Therefore, $f(\bar{\pi})$ satisfying (38) must fall while $\bar{\pi}$ should fall given $f^{\prime}(\bar{\pi})<0$. One can similarly use (37) and (38) to show that the threshold inflation rises with $d, \kappa$ and falls with $\bar{e}, w^{u}$.

The threshold inflation is the inflation rate at which the surplus under both NB and EW regimes is the same. It follows from (37) that the worker's surplus under EW regime varies negatively with the inspection rate and positively with the disutility of effort whereas the surplus under the NB regime depends positively on advertising costs and workers bargaining power. An increase in bargaining power for example, by increasing the relative surplus under the NB regime would necessitate a rise in threshold inflation in order to restore parity between the two regimes. Using the same kind of argument it is easy to see that the threshold inflation will rise with an increase in inspection rates and advertising costs and decrease with disutility of effort and unemployment benefits. 


\section{Impulse Responses}

To evaluate policy outcomes we calibrate the model. The baseline values for the model parameters are set to standard values in the literature and are given in Table 1. We assume that the period length is one quarter and set $\beta=0.99$. We impose the Hosios condition in steady state by setting $b=1-\alpha$. Estimates of $\alpha$, the elasticity of matches with respect to vacancies, generally fall within the 0.4 to 0.6 range. So we set its value at 0.5 . The US unemployment rate averaged $5.84 \%$ over the 1983-2007 period, so we set $\chi$ in the matching function to set steady state employment to equal 0.9416. Following Ravenna and Walsh (2011),

we calibrate the replacement ratio $\frac{w^{u}}{w}$ at 0.54 , the separation rate $\rho$ at $10 \%$ and $q=0.7$. We calibrate our model so that $w^{N B}=w^{E W}$ at the initial steady state. This means that the threshold values of inflation and labor market tightness are $\bar{\pi}=1.04$ and $\bar{\theta}=0.8817$, respectively.

\subsection{Permanent Shock}

In this section, we look at a disinflation experiment, that is, an unanticipated and permanent reduction in the inflation target of the central bank. Figure 1 shows the path of output, inflation, real wages and nominal interest rate in response to such a policy change under the following regimes (1) no labor market frictions (2) both shirking and search and matching frictions in the labor market. Notice that in both the cases there are two effects in play. The permanent decrease in the rate of inflation diminishes the price dispersion, and acts like a positive productivity shock. The productivity increase outweighs the contractionary effect of the disinflationary shock thereby causing output to rise and inflation to fall in the long run. The permanent decrease in the rate of inflation diminishes the price dispersion, and acts like a positive productivity shock. The productivity increase outweighs the contractionary effect of the disinflationary shock thereby 
causing output to rise and inflation to fall in the long run. ${ }^{5}$ In the case without labor market frictions, the economy is always at its full employment and the rise in wages is higher than the case with labor market frictions.

\section{Welfare}

Our objective in this section is to compute the welfare costs of disinflations in the presence of labor market frictions ${ }^{6}$. In this regard we follow Ascari and Ropele (2012) who compute both short-run as well as long-run welfare costs of inflation. They show that the welfare loss due to disinflation may be calculated as the difference between the value function at time zero, $V_{0}$ (when the disinflation is actually implemented) and the value function at the initial steady state of inflation, termed $V_{\text {old }}$. Formally their measure of welfare loss is given by

$$
W S R=-\left(\frac{V_{0}-V_{\text {old }}}{\pi_{\text {old }}^{*}-\pi_{\text {new }}^{*}}\right)
$$

The expression for $V_{\text {old }}$ is given by

$$
V_{\text {old }}=\frac{1}{1-\beta}\left[C_{\text {old }}-\bar{e} N_{\text {old }}\right]
$$

where $C_{\text {old }}$ and $N_{\text {old }}$ denote respectively consumption and employment. The value of $V_{0}$ is available from the numerical simulation of the model.

Note that $W S R$ measures both transitional dynamics as well as the longrun effects of disinflation. It follows from the formula that the welfare based sacrifice ratio is positive if disinflation reduces welfare. The difference $V_{0}-V_{\text {old }}$ can be converted into consumption equivalent units which is defined as a constant fraction of steady state consumption that households are willing to give up in each

\footnotetext{
${ }^{5}$ Our framework is unable to capture the rise in nominal interest rates and the recession that accompany a disinflation. The fall in the interest rate happens due to the Fisher effect and the rise in output is dues to the reduction in price dispersion. This is a shortcoming of our framework and we thank the refree for bringing this to our attention.

${ }^{6}$ The analysis in this section closely follows Ascari and Ropele (2012).
} 
period in order to avoid the disinflation policy. This constant fraction of steady state consumption $\lambda$, can be obtained by solving the following equation

$$
V_{0}=\frac{1}{1-\beta}\left[(1-\lambda) C_{o l d}-e N_{o l d}\right]
$$

Thus, the consumption equivalent measure is given by

$$
\lambda=\frac{(1-\beta)\left(V_{\text {old }}-V_{0}\right)}{C_{\text {old }}}
$$

The measure of welfare obtained is given by

$$
S R^{W}=\frac{\lambda}{\pi_{\text {old }}^{*}-\pi_{\text {new }}^{*}}
$$

The long-run cost of disinflation in terms of consumption equivalent units is given by

$$
\lambda_{\infty}=\frac{(1-\beta)\left(V_{\text {old }}-V_{\text {new }}\right)}{C_{\text {old }}}
$$

where $V_{\text {new }}$ and $V_{\text {old }}$ denote the value function in the new and old inflation steady states, respectively. The long-run welfare based measure is then defined as

$$
S R_{\infty}^{W}=\frac{\lambda_{\infty}}{\pi_{\text {old }}^{*}-\pi_{\text {new }}^{*}}
$$

The short-run welfare measure is given by

$$
S R^{W}-S R_{\infty}^{W}=\frac{(1-\beta)\left(V_{\text {new }}-V_{0}\right)}{C_{\text {old }}}
$$

Table 2 reports the long-run welfare gains and the short-run welfare costs in consumption equivalent units under alternate regimes. Specifically, we examine welfare under the regimes of (1) no labor market frictions (2) shirking and search frictions in the labor market with NB wages (3) shirking and search frictions in the labor market with EW wages. It follows from Table 2 that the long-run welfare gain is higher in the model with labor market frictions. Intuitively, in the model without labor market frictions labor is always at full employment. The gains in output come solely from an increase in productivity due to disinflation. 
On the other hand, with labor market frictions the increase in output arises from both an increase in productivity as well as an increase in employment.

Consider now the case with labor market frictions. In the case of both the $\mathrm{NB}$ and EW regimes the total welfare gains $\left(S R^{W}\right)$ quantitatively dominate the short run welfare costs $\left(S R^{W}-S R_{\infty}^{W}\right)$. This would imply that the long-run welfare gains $S R_{\infty}^{W}$ dominate the short-run welfare costs $\left(S R^{W}-S R_{\infty}^{W}\right)$. Interestingly, it also follows from Table 2 that while the short-run costs of disinflation are lower under the NB regime, the total welfare gains are higher under the EW regime.

Figure 2 displays the path of consumption, unemployment, real wage and utility function under the NB and the EW regimes. In the case of both the regimes the disinflation causes consumption and output to rise on impact. As firms increase production, there is an increase in the vacancies posted and the labor market tightens. As a consequence real wage increases and unemployment falls. The latter variables move in the opposite direction with respect to vacancies thereby reproducing the Beveridge curve. In a tight labor market, workers are in a strong position in the bargaining and the surplus value of a match to a worker is high. Consequently, NB wages are larger then EW wages and the threat to shirk is non-credible. To summarize in the face of disinflationary shocks if there is both shirking as well as search and matching frictions in the labor market then NB wages prevail as they are higher. The lower wages under the EW regime result in higher output in the long run when compared to the NB regime. This then results in higher welfare gains under the EW regime in the long run. However the rigidity of wages under the EW regime also causes output to be slow to adjust to its long-run level when compared to the NB regime. This results in higher welfare costs under the EW regime in the short run.

It is interesting to note that though wages tend to be higher under a NB regime, welfare tends to be higher under an EW regime. Essentially, the surplus from shirking is low when there is a permanent disinflationary shock and this 
results in higher NB wages when compared to EW wages. However, if wages were restricted to EW wages when there is a disnflationary shock, then the relatively lower wages under this regime would in the long run be welfare improving. This is because the lower wages under this regime result in more job posting and lower unemployment and hence higher output when compared to the NB regime.

In our model as in Ascari (2004), Levin and Yun (2007), and Yun (2005) the deviation of steady-state output from its natural rate becomes larger as trend inflation rises. Thus the natural rate hypothesis does not hold in our setup. Higher trend inflation widens the dispersion of relative prices of differentiated goods in the presence of unchanged prices, because it causes price-adjusting firms to set a higher price and non-adjusting firms' relative prices to erode more severely. Therefore, it increases the dispersion of demand for the goods and generates a larger loss in aggregate output. Thus reduction in the inflation rate does result in an improvement in the welfare. This is demonstrated in Figure 3 which plots the welfare gains due to disinflation in the model with both labor market frictions. It would appear from the figure that an inflation rate of zero would be the welfare maximizing inflation rate.

\section{Conclusion}

This paper analyzes disinflations in a New Keynesian model that includes both search and matching as well as shirking in the labor market. These features imply that in addition to workers having bargaining rights there is a lower bound on workers' match surplus. Our objective is to study the wage formation process in this milieu. Furthermore, we also evaluate the welfare costs of disinflation under both a NB regime as well as an EW regime. Since our exercise involves comparison of dynamics across steady states, we carry out our analysis in a nonlinear framework. 
We find that in the event of a permanent disinflationary shock NB wage is always higher than EW wages. Intuitively a permanent disinflationary shock acts like a positive productivity shock by reducing the distortion due to price dispersion. This outweighs the contactionary effect of the disinflation causing output to rise This increased worker surplus means that the NSC does not bind resulting in an NB regime. When evaluated from a welfare perspective we find that welfare gains under disinflation are highest in the case where the economy has EW wages. Essentially the lower wages under the EW regime result in a higher output and hence higher welfare under the EW regime.

In conclusion, our paper studies the wage formation process and welfare costs of disinflation in the presence of labor market frictions. The analysis was carried out in a simple framework with both search and matching frictions and moral hazard in the labor market. One could add additional frictions such as a cost channel. Such a friction is likely to generate tensions that could reduce the output gains from disinflations and make the analysis more complicated. We however do not believe it will alter the key implications of the model. An interesting extension would be to study optimal monetary policy in our setup. We leave this exercise for future work. 


\section{References}

[1] Ascari, Guido 2004. "Staggered Prices and Trend Inflation: Some Nuisances," Review of Economic Dynamics, Vol. 7, No. 3, pp. 642-667.

[2] Ascari, Guido and Christian Merkl. 2009. "Real Wage Rigidities and the Cost of Disinflations," Journal of Money, Credit, and Banking, 41(2): 417-435.

[3] Ascari, Guido and Tiziano Ropele, 2012, "Disinflation in a DSGE Perspective: Sacrifice Ratio or Welfare Gain Ratio?," Journal of Economic Dynamics And Control, Vol. 36, pp. 169-182.

[4] Blanchard, Olivier J. and Jordi Galí. 2007. "Real Wage Rigidities and the NK Model," Journal of Money, Credit, and Banking, supplement to 39(1): 35-66.

[5] Faia, Esther. 2008. "Optimal Monetary Policy Rules with Labor Market Frictions," Journal of Economic Dynamics and Control, 32(5): 1600-1621.

[6] Gertler, Mark, Luca Sala, and Antonella Trigari. 2008. "An Estimated Monetary DSGE Model with Unemployment and Staggered Nominal Wage Bargaining," Journal of Money, Credit and Banking, 40: 1713-1770.

[7] Gertler, Mark and Antonella Trigari. 2009. "Unemployment Fluctuations with Staggered Nash Wage Bargaining," Journal of Political Economy, $117(1): 38-86$.

[8] James Costain \& Marcel Jansen, 2010. "Employment Fluctuations with Downward Wage Rigidity: The Role of Moral Hazard," Scandinavian Journal of Economics, 112(4), 782-811.

[9] Krause, Michael U. and Thomas A. Lubik. 2007. "The (Ir)relevance of Real Wage Rigidity in the NK Model with Search Frictions," Journal of Monetary Economics, 54(3): 706-727. 
[10] Krause, Michael U., David J. Lopéz-Salido, and Thomas A. Lubik. 2008. "Do Search Frictions Matter for Inflation Dynamics?," European Economic Review, 52(8): 1464-1479.

[11] Levin, Andrew, and Tack Yun. (2007) "Reconsidering the Natural Rate Hypothesis in a New Keynesian Framework," Journal of Monetary Economics, $54,1344-1365$

[12] Ravenna, Federico and Carl E. Walsh. 2008. "Vacancies, Unemployment, and the Phillips Curve." European Economic Review, 52: 1494-1521.

[13] Ravenna, Federico and Carl E. Walsh. 2011. ".Welfare-based optimal monetary policy with unemployment and sticky prices: A linear-quadratic framework," AEJ Macroeconomics 3: 130-162.

[14] Rocheteau, Guillaume, 2001. "Equilibrium unemployment and wage formation with matching frictions and worker moral hazard," Labour Economics, $8(1), 75-102$.

[15] Schmitt-Grohé, Stephanie, and Uribe, Martín (2007): "Optimal Simple and Implementable Monetary and Fiscal Rules," Journal of Monetary Economics, 54, 1702-1725.

[16] Thomas, Carlos. 2008. "Search and Matching Frictions and Optimal Monetary Policy," Journal of Monetary Economics, 55: 936-956.

[17] Trigari, Antonella. 2009. "Equilibrium Unemployment, Job Flows and Inflation Dynamics," Journal of Money, Credit and Banking, 41: 1-33.

[18] Yun, Tack. (2005) "Optimal Monetary Policy with Relative Price Distortions," American Economic Review, 95, 89-109 


\section{A Appendix}

\section{A.1 Wholesale Firm}

Let $\Pi_{i, t}^{w}$ denote the firm $i$ 's period $t$ profit. The wholesale firm's problem is to maximize

$$
E_{t} \sum_{j=0}^{\infty} \beta^{j} \Pi_{i, t+j}^{w}
$$

where

$$
\Pi_{i, t+j}^{w}=\mu_{t+j}^{-1} Y_{i, t+j}^{w}-\kappa v_{i, t+j}-w_{t+j} N_{i, t+j}
$$

subject to (4) and (9). The first order conditions for the firm's problem are

$$
\begin{gathered}
\frac{1}{\mu_{t}}=\psi_{i t} \\
-\kappa=\varphi_{i t} q_{t} \\
\frac{1}{\mu_{t}}=w_{t}-\varphi_{i t}+\beta(1-\rho) E_{t}\left(\frac{\lambda_{t+1}}{\lambda_{t}}\right) \varphi_{i, t+1}
\end{gathered}
$$

where $\varphi$ and $\psi$ are the multipliers associated with (4) and (9) respectively. Combining (A.1)-(A.3) we get

$$
w_{t}=\frac{1}{\mu_{t}}-\frac{\kappa}{q_{t}}+\beta(1-\rho) E_{t} \frac{\kappa}{q_{t+1}}
$$

which is equation (16) in the text. Let $V_{t}^{J}$ and $V_{t}^{V}$ be the value of a filled job and vacancy respectively. Then

$$
V_{t}^{V}=-\kappa+q\left(\theta_{t}\right) V_{t}^{J}+\left[1-q\left(\theta_{t}\right)\right] \beta E_{t} V_{t+1}^{V}
$$

Under free entry $V_{t}^{V}=0$, the value of a vacancy is zero in equilibrium. This then implies

$$
V_{t}^{J}=\frac{\kappa}{q\left(\theta_{t}\right)}
$$

\section{A.2 Inflation}

Let $\frac{P_{t+i}}{P_{t}}$ denote the cumulative gross inflation between $t$ and $t+i$. Then, we can write $\frac{P_{t+i}}{P_{t}}$ in (6) as

$$
\frac{P_{t+i}}{P_{t}}=\prod_{j=0}^{i-1} \frac{P_{t+1+j}}{P_{t}}=\prod_{j=1}^{i} \pi_{t+j}=\pi_{t, t+i}
$$


We can then write (6) as

$$
\frac{P_{t}(j)}{P_{t}}=\left(\frac{\epsilon}{\epsilon-1}\right)\left(\frac{\psi_{t}}{\phi_{t}}\right)
$$

where

$$
\begin{aligned}
& \Psi_{t}=E_{t} \sum_{i=0}^{\infty}(\omega \beta)^{i}\left[\pi_{t, t+i}^{\epsilon} Y_{t+i}(j) m c_{t+i}\right] \\
& \Phi_{t}=E_{t} \sum_{i=0}^{\infty}(\omega \beta)^{i}\left[\pi_{t, t+i}^{\epsilon-1} Y_{t+i}(j)\right]
\end{aligned}
$$

Following Ascari and Merkl (2009) we can write the above two equations recursively as

$$
\begin{gathered}
\Psi_{t}=Y_{t} m c_{t}+\omega \beta E_{t}\left[\pi_{t+1}^{\epsilon} \Psi_{t+1}\right] \\
\Phi_{t}=Y_{t}+\omega \beta E_{t}\left[\pi_{t+1}^{\epsilon-1} \Phi_{t+1}\right]
\end{gathered}
$$

After some manipulation it can be shown that the aggregate price level evolves according to

$$
1=\left[\omega \pi_{t}^{\epsilon-1}+(1-\omega)\left(\frac{P_{t}(j)}{P_{t}}\right)^{1-\epsilon}\right]^{\frac{1}{1-\epsilon}}
$$

which is equation (7) in the text.

\section{A.3 Derivation of Price Dispersion}

Let $s_{t}=\int_{0}^{1}\left(\frac{P_{t}(j)}{P_{t}}\right)^{-\epsilon} d j$. Then, by sticky price's a la Calvo,

$$
\begin{aligned}
s_{t} & =\int_{0}^{1}\left(\frac{P_{t}(j)}{P_{t}}\right)^{-\epsilon} d j \\
& =(1-\omega)\left(\frac{\widetilde{P}_{t}}{P_{t}}\right)^{-\epsilon}+(1-\omega) \omega\left(\frac{\widetilde{P}_{t-1}}{P_{t}}\right)^{-\epsilon}+(1-\omega) \omega^{2}\left(\frac{\widetilde{P}_{t-2}}{P_{t}}\right)^{-\epsilon}+\ldots \\
& =(1-\omega)\left(\frac{\widetilde{P}_{t}}{P_{t}}\right)^{1-\epsilon}+\omega\left(\frac{P_{t-1}}{P_{t}}\right)^{-\epsilon}\left[(1-\omega)\left(\frac{\widetilde{P}_{t-1}}{P_{t-1}}\right)^{-\epsilon}+(1-\omega) \omega\left(\frac{\widetilde{P}_{t-2}}{P_{t-1}}\right)^{-\epsilon}+\ldots\right] \\
& =(1-\omega)\left(\frac{\widetilde{P}_{t}}{P_{t}}\right)^{1-\epsilon}+\omega \pi_{t}^{\epsilon} s_{t-1}
\end{aligned}
$$

where $\widetilde{P}_{t}=P_{t}(j)$ by symmetry. This is eq (26) in the text. 


\section{A.4 Inflation in Steady State}

The steady state value of $\frac{P(j)}{P}$ follows from (7) and is given by

$$
\frac{P(j)}{P}=\left(\frac{1-\omega \bar{\pi}^{\epsilon-1}}{1-\omega}\right)^{\frac{1}{1-\epsilon}}
$$

This in turn pins down price dispersion which follows from (26)

$$
s=\frac{(1-\omega)\left(\frac{P(j)}{P}\right)^{-\epsilon}}{\left(1-\omega \bar{\pi}^{\epsilon}\right)}
$$

Thus in steady state inflation and dispersion are inversely related to each other. It then follows from (A.6), (A.8) and (A.9) that

$$
\begin{gathered}
\frac{P(j)}{P}=\frac{\epsilon}{\epsilon-1} \frac{\Psi}{\Phi} \\
\Psi=\frac{Y}{\mu} \frac{1}{\left(1-\omega \beta \bar{\pi}^{\varepsilon}\right)} \\
\Phi=Y \frac{1}{\left(1-\omega \beta \bar{\pi}^{\varepsilon-1}\right)}
\end{gathered}
$$

Further, it follows from (7) and (26) that

$$
1=\omega \bar{\pi}^{\varepsilon-1}+(1-\omega)\left(\frac{P(j)}{P}\right)^{1-\varepsilon}
$$

Combining (A.11) - (A.13), we get

$$
\begin{aligned}
\frac{P(j)}{P} & =\frac{\epsilon}{\epsilon-1} \frac{\frac{Y}{\mu} \frac{1}{\left(1-\omega \beta \bar{\pi}^{\varepsilon}\right)}}{Y \frac{1}{\left(1-\omega \beta \bar{\pi}^{\varepsilon-1}\right)}} \\
& =\frac{\epsilon}{\epsilon-1} \frac{1}{\mu} \frac{\left(1-\omega \beta \bar{\pi}^{\varepsilon-1}\right)}{\left(1-\omega \beta \bar{\pi}^{\varepsilon}\right)}
\end{aligned}
$$

Then plug (A.15) into (A.14) to get,

$$
1=\omega \bar{\pi}^{\varepsilon-1}+(1-\omega)\left[\frac{\epsilon}{\epsilon-1} \frac{1}{\mu} \frac{\left(1-\omega \beta \bar{\pi}^{\varepsilon-1}\right)}{\left(1-\omega \beta \bar{\pi}^{\varepsilon}\right)}\right]^{1-\varepsilon}
$$

This is equation (7) in the text. 


\section{A.5 Steady state value of wages}

\section{A.5.1 Efficiency Wage Equilibria}

Combine (28) and (29) to get the efficiency wage

$$
w^{E W}=(1-\beta(1-\rho)(1-\theta q)) \frac{\bar{e}}{d}+\beta(1-\rho)(1-\theta q)\left(\bar{e}+w^{u}\right)
$$

Substituting (A.17) into (28) we obtain the steady state value of the employment surplus under EW regime

$$
V^{E}-V^{U}=\frac{w-\bar{e}-w^{u}}{1-\beta(1-\rho)(1-\theta q)}
$$

This is equation (28) in the text.

\section{A.5.2 Nash Bargaining Wages}

The steady state value of being employed follows from (10) and is given by

$$
r V^{E}=(w-\bar{e})(1+r)+\rho(1-\theta q)\left(V^{u}-V^{E}\right)
$$

The steady state value of unemployment follows from (11)

$$
r V^{U}=w^{u}(1+r)+\theta q\left(V^{E}-V^{U}\right)
$$

The Nash bargaining solution in steady state is given by

$$
\left(V^{E}-V^{U}\right)=\frac{b}{(1-b)} V^{J}
$$

Now substituting (A.20) in (A.18) we get

$$
r V^{E}=(w-\bar{e})(1+r)-\frac{\rho(1-\theta q) b}{(1-b)} V^{J}
$$

Once again substituting for $r V^{E}$ from (A.20) we get

$$
\frac{b}{(1-b)}\left[r V^{J}+\rho(1-\theta q) V^{J}\right]=(w-\bar{e})(1+r)-r V^{U}
$$

Using (30) and simplifying we get the NB wage to be

$$
w^{N B}=b\left(\frac{1}{f(\bar{\pi})}-\frac{\rho \kappa \theta}{(1+r)}\right)+(1-b)\left[\bar{e}+\frac{r V^{U}}{1+r}\right]
$$


In other words the NB wage in steady state is a weighted average of the workers productivity and the workers reservation wage. Substituting (A.20) in (A.19) we get

$$
r V^{U}=w^{u}(1+r)+\theta q \frac{b}{(1-b)} V^{J}
$$

Now substituting for $V^{J}$ from (A.20) we get

$$
r V^{U}=w^{u}(1+r)+\frac{\theta b \kappa}{(1-b)}
$$

Substituting this in (A.22) we get

$$
w^{N B}=b\left[\frac{1}{f(\bar{\pi})}+\frac{\theta \kappa(1-\rho)}{1+r}\right]+(1-b)\left(\bar{e}+w^{u}\right)
$$

This is equation (34) in the text. 
Table 1. Baseline Parameters

\begin{tabular}{ccl}
\hline Parameter & Value & \multicolumn{1}{c}{ Note } \\
$\beta$ & 0.99 & Discount factor \\
\hline$\omega$ & 0.7 & Calvo sticky price parameter \\
\hline$\epsilon$ & 6 & Elasticity of substitution \\
\hline$\alpha$ & 0.5 & Matching elasticity \\
\hline$b$ & 0.5 & Bargaining power of workers \\
\hline$\rho$ & 0.1 & Job separation ratio \\
\hline$w^{u} / w$ & 0.54 & Replacement ratio \\
\hline$d$ & 0.1 & Shirking detection rate \\
\hline $\bar{e}$ & 0.09 & To set $w^{N B}=w^{E W}$ for initial steady state \\
\hline$N$ & 0.9416 & Labor force \\
\hline$q$ & 0.7 & Probability of filling a vacancy (initial steady state)
\end{tabular}

Table 2. Welfare Loss of 1\%p Disinflation Policy Under Each Regime

\begin{tabular}{|c|c|c|c|c|}
\hline \multicolumn{5}{|c|}{ No Labor Friction } \\
\hline Initial $\pi$ & WSR & $S R^{W}$ & $S R_{\infty}^{W}$ & $S R_{\text {Short-run }}^{W}$ \\
\hline $4 \%$ & -11.812 & -0.126 & -0.131 & 0.005 \\
\hline $3 \%$ & -11.725 & -0.125 & -0.130 & 0.005 \\
\hline $2 \%$ & -7.785 & -0.083 & -0.086 & 0.003 \\
\hline $1 \%$ & -4.768 & -0.051 & -0.053 & 0.002 \\
\hline \multicolumn{5}{|c|}{ Labor Frictions with NB Wages } \\
\hline Initial $\pi$ & WSR & $S R^{W}$ & $S R_{\infty}^{W}$ & $S R_{\text {Short-run }}^{W}$ \\
\hline $4 \%$ & -12.665 & -0.141 & -0.146 & 0.005 \\
\hline $3 \%$ & -12.572 & -0.140 & -0.144 & 0.005 \\
\hline $2 \%$ & -8.718 & -0.097 & -0.100 & 0.003 \\
\hline $1 \%$ & -4.781 & -0.053 & -0.054 & 0.001 \\
\hline \multicolumn{5}{|c|}{ Labor Frictions with EW Wages } \\
\hline Initial $\pi$ & WSR & $S R^{W}$ & $S R_{\infty}^{W}$ & $S R_{\text {Short-run }}^{W}$ \\
\hline $4 \%$ & -14.415 & -0.160 & -0.166 & 0.006 \\
\hline $3 \%$ & -14.309 & -0.159 & -0.165 & 0.006 \\
\hline $2 \%$ & -9.522 & -0.106 & -0.109 & 0.003 \\
\hline $1 \%$ & -5.684 & -0.063 & -0.065 & 0.002 \\
\hline
\end{tabular}


Figure 1. Impulse Response After a 1\%p Permanent Policy Shock
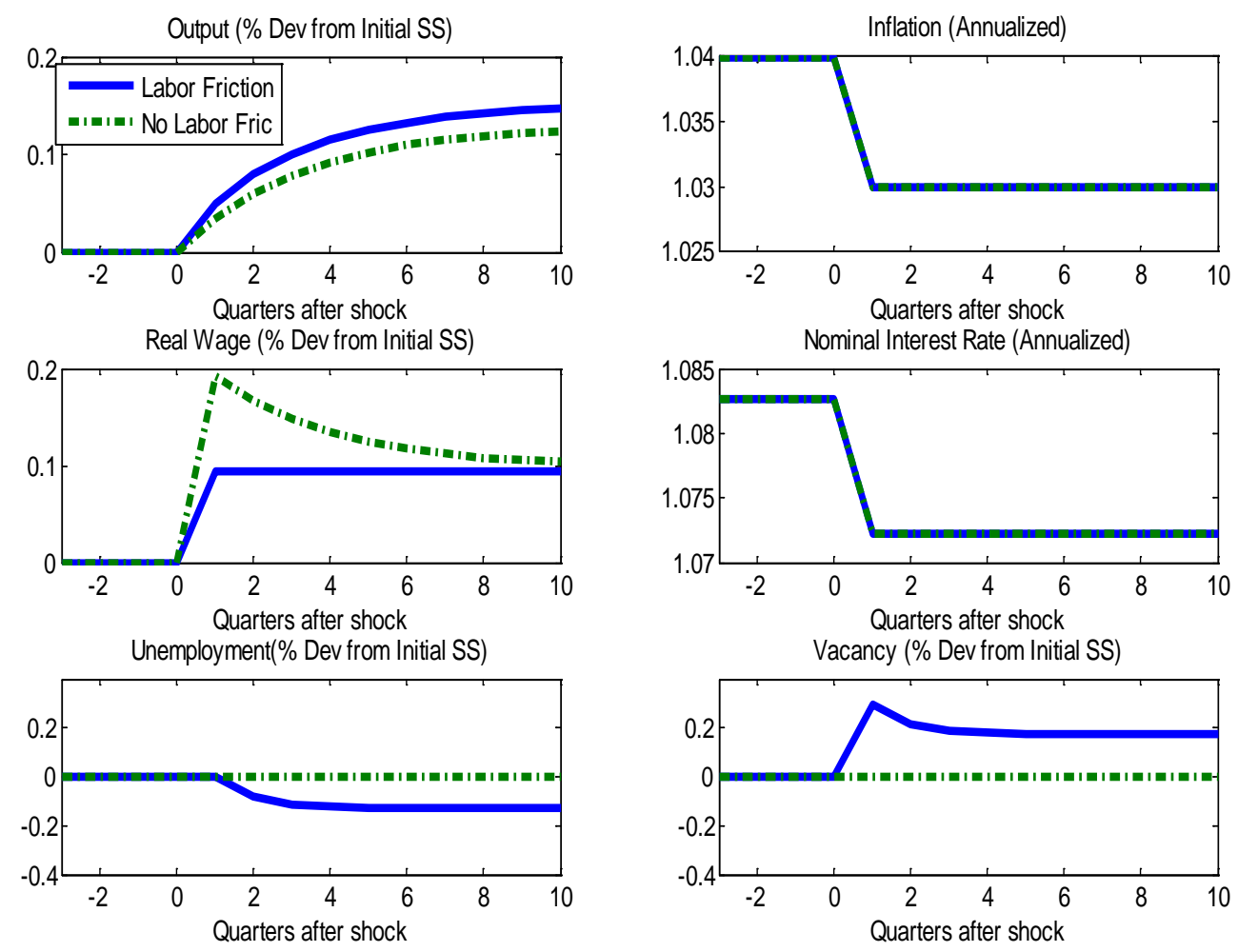

*The initial and terminal target inflation rates of the central bank are $4 \%$ and $3 \%$ per annum, respectively. 
Figure 2. NB vs. EW- Impulse Response After 1\%p Permanent Disinflation Shock
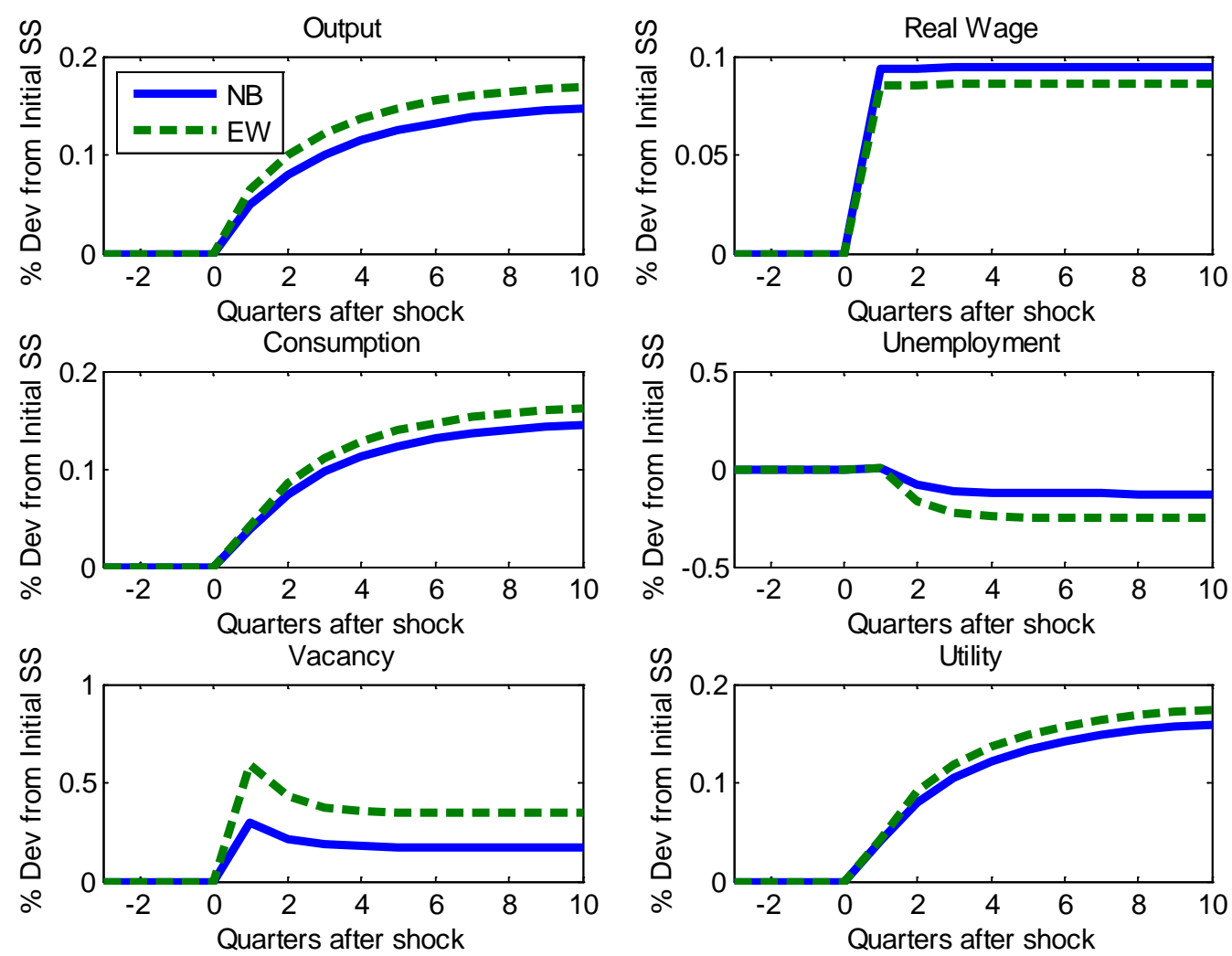

*The initial and terminal target inflation rates of the central bank are $4 \%$ and $3 \%$ per annum, respectively. 
Figure 3. Long-run Welfare Loss of 1\%p Permanent Disinflation Policy

\begin{tabular}{|c|c|c|c|c|c|}
\hline \multirow{2}{*}{0.000} & \multicolumn{5}{|c|}{ Initial Inflation } \\
\hline & $4 \%$ & $3 \%$ & $2 \%$ & $1 \%$ & $0 \%$ \\
\hline-0.020 & & & & & \\
\hline-0.040 & & & & & \\
\hline-0.060 & & & & & \\
\hline-0.080 & & & & & \\
\hline-0.100 & & & & & \\
\hline-0.120 & & & & & \\
\hline-0.140 & & & & & \\
\hline-0.160 & & & & & \\
\hline
\end{tabular}

